\title{
Storage Property Is Positively Correlated With Antioxidant Capacity in Different Sweet Potato Cultivars
}

\author{
Hui-Hui Song ${ }^{1+}$, Zhi-Lin Zhou't, Dong-Lan Zhao't, Jun Tang', Yan-Hong $\mathrm{Li}^{1}$, Zhuo Han', \\ Xiao-Yan Chen ${ }^{1}$, Kang-Di Hu' ${ }^{1 *}$ Gai-Fang Yao ${ }^{1 *}$ and Hua Zhang ${ }^{\text {** }}$ \\ ${ }^{1}$ School of Food and Biological Engineering, Hefei University of Technology, Hefei, China, ${ }^{2}$ Xuzhou Institute of Agricultural \\ Sciences of the Xuhuai District of Jiangsu Province, Xuzhou, China
}

\section{OPEN ACCESS}

Edited by:

Mostafa Abdelwahed

Abdelrahman,

Aswan University, Egypt

Reviewed by:

Mohammad Golam Mostofa,

Bangabandhu Sheikh Mujibur

Rahman Agricultural University,

Bangladesh

Seyed Morteza Zahedi,

University of Maragheh, Iran

*Correspondence:

Kang-Di Hu

kangdihu@hfut.edu.cn

Gai-Fang Yao

yaogaifang@hfut.edu.cn

Hua Zhang

hzhanglab@hfut.edu.cn

${ }^{\dagger}$ These authors have contributed equally to this work and share first authorship

Specialty section:

This article was submitted to

Crop and Product Physiology,

a section of the journal

Frontiers in Plant Science

Received: 30 May 2021 Accepted: 20 October 2021 Published: 23 November 2021

Citation:

Song H-H, Zhou Z-L, Zhao D-L,

Tang J, Li Y-H, Han Z, Chen X-Y,

Hu K-D, Yao G-F and Zhang H (2021)

Storage Property Is Positively Correlated With Antioxidant Capacity in Different Sweet Potato Cultivars.

Front. Plant Sci. 12:696142.

doi: 10.3389/fpls.2021.696142
Sweet potato decays easily due to its high respiration rate and reactive oxygen species (ROS) accumulation during postharvest storage. In this study, we explored the relationship between antioxidant capacity in leaves and storage properties in different sweet potato cultivars, the tuberous roots of 10 sweet potato cultivars were used as the experimental materials to analyze the storage property during storage at $11-15^{\circ} \mathrm{C}$. According to the decay percentage after 290 days of storage, Xu 32 was defined as a storage-tolerant cultivar (rot percentage less than 25\%); Xu 55-2, Z 15-1, Shangshu 19, Yushu, and Zhezi 3 as above-moderate storage-tolerant cultivars (rot percentage ranging from 25 to 50\%); Sushu 16, Yanshu 5, and Hanzi as medium-storable cultivars (rot percentage 50-75\%); and Yan 25 as a storage-sensitive cultivar (rot percentage greater than $75 \%$ ). Meanwhile, analysis of the $\alpha$-amylase activity in root tubers of the 10 sweet potato cultivars during storage indicated that $\alpha$-amylase activity was lowest in the storage-tolerant cultivar Xu 32 and highest in the storage-sensitive cultivar Yan 25. Evaluation of antioxidant enzyme activities and ROS content in the leaves of these 10 cultivars demonstrated that cultivar Xu 32, which showed the best storage property, had higher antioxidant enzyme activity [superoxide dismutase (SOD), catalase (CAT), ascorbate peroxidase (APX), and peroxidase (POD)] but lower lipoxygenase (LOX) activity, hydrogen peroxide $\left(\mathrm{H}_{2} \mathrm{O}_{2}\right)$ and malondialdehyde (MDA) contents, and superoxide anion radical $\left(\mathrm{O}_{2} \cdot{ }^{-}\right)$production rates compared with those of the storagesensitive cultivar Yan 25 and the medium-storability cultivars Hanzi, Yanshu 5, and Sushu 16. Additionally, principal component analysis (PCA) suggested that sweet potato cultivars with different storage properties were clustered separately. Correlation and heat map analysis further indicated that CAT, APX, POD, and SOD activities were negatively correlated with $\alpha$-amylase activity, while LOX activity and MDA and $\mathrm{H}_{2} \mathrm{O}_{2}$ contents were negatively correlated with the storage property of sweet potato. Combined, our findings revealed that storage property is highly correlated with antioxidant capacity in sweet potato leaves and negatively correlated with $\alpha$-amylase activity in tuberous roots, which provides a convenient means for the screening of storage-tolerant sweet potato cultivars.

Keywords: sweet potato, storage property, antioxidant capacity, reactive oxygen species (ROS), correlation analysis 


\section{INTRODUCTION}

Sweet potato (Ipomoea batatas L.), which was domesticated in tropical America, is gradually becoming one of the main food crops worldwide (Mwanga et al., 2017). According to the Food and Agriculture Organization (FAO) of the United Nations, global sweet potato production exceeded 140 million tons in 2019, with China accounting for the largest plantation area (FAO, 2019). Sweet potatoes are rich in many nutrients such as vitamins, dietary fiber, and minerals, as well as other ingredients that are beneficial to human health, including flavonoids, carotenoids, and anthocyanins (Wang et al., 2016; Kang et al., 2017). Additionally, starch is the major component of the storage root of sweet potato, accounting for $50-80 \%$ of its dry matter (Zhang et al., 2017). Amylase activity has been reported to change in sweet potato roots during storage (Takahata et al., 1995; Zhang et al., 2002). Sweet potato tubers are relatively difficult to store long-term due to their high moisture content and respiration rate, as well as the deterioration of the quality of its flesh during postharvest (Sugri et al., 2017). During postharvest storage, endogenous $\alpha$-amylase and $\beta$-amylase enzyme activities influence the starch structure and reduce the starch content, which greatly affects the commodity value of this tuberous root (Lu et al., 2020). Sweet potato is also susceptible to chilling injury owing to its tropical origins (Li et al., 2018). Combined, these observations are indicative of the importance of postharvest storage for the industrial application of sweet potatoes.

Postharvest senescence includes the loss of texture, membrane injury, and decay (Ali et al., 2020). During postharvest storage, many crops produce reactive oxygen species (ROS), such as hydrogen peroxide $\left(\mathrm{H}_{2} \mathrm{O}_{2}\right)$, hydroxyl radicals $(\cdot \mathrm{OH})$, superoxide anion radicals $\left(\mathrm{O}_{2} \cdot{ }^{-}\right)$, and singlet oxygen, which contribute to deteriorative changes, such as lipid peroxidation, DNA mutation, enzyme inactivation, and protein denaturation (Tian et al., 2013). Consequently, ROS generation is considered the main reason for the progression of senescence (Mittler, 2002). To resist ROS-mediated damage, plants have evolved a system that maintains a balance between ROS production and elimination involving enzymatic [superoxide dismutase (SOD; EC 1.15.1.1), catalase (CAT; EC 1.11.1.6), ascorbate peroxidase (APX; EC 1.11.1.11), and peroxidase (POD; EC 1.11.1.7)] and non-enzymatic antioxidants (Miśkiewicz et al., 2000). Despite this, ROS accumulation may exceed the antioxidant capacity, leading to membrane lipid peroxidation and impaired cellular functions (Lurie et al., 1991). Several studies have demonstrated that some plants can delay senescence by eliminating excessive ROS through enhanced antioxidant systems (Zimmermann et al., 2006; Qin et al., 2009). For instance, ultrasonic treatment was shown to effectively decrease the activities of PPO and POD and increase total antioxidant capacity, which help to inhibit the browning of fresh-cut sweet potato, thereby prolonging its postharvest shelf life (Pan et al., 2020). This indicates that antioxidant enzyme capacity is positively correlated with delayed senescence in postharvest fruits and vegetables, which can help prolong their shelf life.

Several studies have investigated the optimization of storage conditions during postharvest sweet potato storage; however, the nature of the endogenous factors that influence the storage characteristics of different sweet potato cultivars remains unclear (Fan et al., 2015; Ji et al., 2017). de Araujo et al. (2021) reported that cold-tolerant sweet potato cultivars have stronger antioxidant enzyme activities compared with those of coldsensitive cultivars, suggestive of the important role of the antioxidant system in eliminating excessive ROS induced by low temperature. Additionally, under optimal storage temperatures, the activities of antioxidant enzymes increase in nectarines and broccoli, thereby prolonging the postharvest storage period (Zhang Z. et al., 2009; Zhao et al., 2018), while greater antioxidant enzyme activity is also associated with better storage performance in sweet potato cultivars (Tang et al., 2019). However, relatively few studies have systematically evaluated the correlation between the antioxidant system and storage property. Moreover, the screening of storage-tolerant sweet potato cultivars based on the storage property of sweet potato tubers is time-consuming and requires specific storage conditions. In this study, 10 sweet potato cultivars were selected to assess the relationship between the storage property of root tubers and the antioxidant capacity of the leaves. The sweet potato root tubers were stored at $11-15^{\circ} \mathrm{C}$ for 290 days, following which the rot percentage, weight loss, and $\alpha$-amylase activity of the different cultivars were assessed, as were differences in antioxidant enzyme activities and ROS-related indexes in the leaves. Furthermore, the relationship between the storage property of the root tubers and the antioxidant capacity of the leaves was investigated by principal component analysis (PCA) and correlation analysis. Combination of this study provides a new method for the rapid screening of sweet potato tuber storability that involves analyzing the biochemical and physiological parameters of sweet potato leaves.

\section{MATERIALS AND METHODS}

\section{Plant Materials and Sample Preparation}

In this study, 10 sweet potato cultivars-Xu 32, Xu 55-2, Z 15-1, Shangshu 19, Sushu 16, Yanshu 5, Hanzi, Yushu, Zhezi 3, and Yan 25-were selected from the National Sweet Potato Improvement Center (Xuzhou, Jiangsu Province, China). Undamaged root tubers of each cultivar (three replicates of $100 \pm 10$ tubers) were harvested in the autumn of 2013-2015 and stored for 290 days at $11-15^{\circ} \mathrm{C}$. The storage property of the sweet potato cultivars was defined according to the decay percentage of the root tubers. Sweet potato cultivars with a rot percentage of less than $25 \%$ were classified as storage-tolerant; those with a rot percentage ranging from 25 to $50 \%$ were classified as above-medium storage-tolerant; those with a rot percentage between 50 and $75 \%$ were classified as medium-storable; and those with a rot percentage higher than 75\% were classified as storage-sensitive (Zhang and Fang, 2006). Each cultivar was assigned a storability score based on the rot percentage. Additionally, the weight loss percentage of the sweet potato tubers was also recorded by determining the tuber weight before and after storage. Tuberous roots without pests, disease, or mechanical damage were selected for the experiment. The stem cuttings of 10 sweet potato cultivars were obtained 
from the National Sweet Potato Improvement Center in May 2016 and planted in the greenhouse at the Hefei University of Technology in Hefei, China, at $24^{\circ} \mathrm{C}$ under a $16 / 8$-h light/dark cycle. After 2 months of growth, the mature leaves (from the second-to-top to the fifth-to-top) of 10 seedlings from each cultivar were sampled, immediately frozen in liquid nitrogen, and ground to a powder. The powder was stored at $-80^{\circ} \mathrm{C}$ for subsequent analysis.

\section{Determination of $\alpha$-Amylase Activity in Sweet Potato Roots}

The $\alpha$-amylase activity in the tuberous roots of the sweet potato cultivars was determined at $0,30,60,90,120,150,180,210,240$, 270 , and 290 days after storage (DAS) as described by Zhang et al. (2009). Sweet potato root samples $(2.0 \pm 0.05 \mathrm{~g})$ were homogenized in $4 \mathrm{ml}$ of $0.1 \mathrm{M} \mathrm{NaAc}$ (including $6 \mathrm{M} \mathrm{CaCl}_{2}, \mathrm{pH}$ 5.0) and centrifuged at $20,000 \times g$ for $20 \mathrm{~min}$. Then, $0.3 \mathrm{ml}$ of the supernatant was mixed with $0.5 \mathrm{ml}$ of $\beta$-limit dextrin and $0.2 \mathrm{ml}$ of $10 \mathrm{mM} \mathrm{NaAc}$ and incubated at $30^{\circ} \mathrm{C}$. After incubation, $5 \mathrm{ml}$ of $0.01 \% \mathrm{I}_{2}-\mathrm{KI}$ and $0.4 \mathrm{ml}$ of $\mathrm{H}_{2} \mathrm{O}$ were added to $0.1 \mathrm{ml}$ of the reaction solution, and the absorbance was determined at $560 \mathrm{~nm}$. One unit of $\alpha$-amylase activity was defined as the amount of enzyme needed to degrade $1 \mathrm{mg}$ of $\beta$-limit dextrin per minute and was represented as $\mathrm{U} / \mathrm{g}$ fresh weight (FW).

\section{Determination of Antioxidant Enzymes (i.e., Peroxidase, Catalase, Ascorbate Peroxidase, and Superoxide Dismutase) in Sweet Potato Leaves}

The POD, CAT, APX, and SOD activities were determined following the method described by Garcia-Limones et al. (2002). Sweet potato leaves $(2.0 \pm 0.05 \mathrm{~g})$ were homogenized in $3 \mathrm{ml}$ of enzyme extract buffer $\left(50 \mathrm{mM} \mathrm{K}_{2} \mathrm{PO}_{4} \mathrm{pH} 7.5\right.$, $1 \mathrm{mM}$ ethylenediaminetetraacetic acid (EDTA), $1 \mathrm{mM}$ phenylmethanesulfonyl fluoride (PMSF), $5 \mathrm{mM}$ ascorbic acid (ASA), and $5 \%$ polyvinylpyrrolidone (PVP)) at $4^{\circ} \mathrm{C}$ and centrifuged at $12,000 \times g$ for $30 \mathrm{~min}$ at $4^{\circ} \mathrm{C}$. After centrifugation, the obtained supernatant was considered the crude enzyme solution.

The SOD activity was determined by the photochemical reduction of nitroblue tetrazolium (NBT) in the presence of riboflavin. One unit of SOD activity was defined as the amount of enzyme that inhibited the reduction of NBT by $50 \%$; SOD activity was expressed as $\mathrm{U} / \mathrm{g} \mathrm{FW}$. The determination of POD activity was based on the increase in absorbance at $470 \mathrm{~nm}$ resulting from the oxidation of guaiacol in the presence of $\mathrm{H}_{2} \mathrm{O}_{2}$. CAT activity was determined as the rate of decrease in absorbance at $240 \mathrm{~nm}$ using $\mathrm{H}_{2} \mathrm{O}_{2}$ as the substrate. APX activity was determined by measuring the changes in absorbance at $290 \mathrm{~nm}$. The reaction system ( $3 \mathrm{ml}$ total volume) included $50 \mathrm{mM}$ phosphate buffer at $\mathrm{pH}$ 7.0, $15 \mathrm{mM}$ ascorbic acid, $15 \mathrm{mM} \mathrm{H}_{2} \mathrm{O}_{2}$, and the appropriate amount of crude enzyme solution. One unit of POD, CAT, or APX activity was defined as an increase or decrease of 0.01 in the absorbance value per minute and was represented as $\mathrm{U} / \mathrm{g} \mathrm{FW}$.

\section{Determination of Superoxide Anion Radical Production, Hydrogen Peroxide, and Malondialdehyde Content in Sweet Potato Leaves}

The $\mathrm{H}_{2} \mathrm{O}_{2}$ content and $\mathrm{O}_{2}{ }^{-}$production were determined according to the methods described by Ge et al. (2017). For the determination of $\mathrm{O}_{2} \cdot{ }^{-}$production, $2 \mathrm{~g}$ of leaf powder was homogenized in $0.1 \mathrm{mM}$ phosphate buffer, $\mathrm{pH} 7.8$, and centrifuged at $12,000 \times g$ for $30 \mathrm{~min}$ at $4^{\circ} \mathrm{C}$; the supernatant was used for $\mathrm{O}_{2} .^{-}$determination. Each sample was divided into an experimental group and a control group. Notably, $1 \mathrm{ml}$ each of the supernatant, $\mathrm{H}_{3} \mathrm{PO}_{4}$ buffer, and $1 \mathrm{mM}$ $\mathrm{HONH}_{3} \mathrm{Cl}$ was mixed in a test tube and incubated at $25^{\circ} \mathrm{C}$ for $1 \mathrm{~h}$. Then, $17 \mathrm{mM} \mathrm{p}$-aminobenzenesulfonic acid and $7 \mathrm{mM}$ $\alpha$-naphthylamine were added and mixed, followed by incubation for an additional $20 \mathrm{~min}$. Absorbance was determined at $530 \mathrm{~nm}$. The $\mathrm{O}_{2} \cdot{ }^{-}$production rate was calculated on an FW basis in $\mu \mathrm{mol} \cdot \mathrm{g}^{-1} \cdot \mathrm{s}^{-1}$. For the determination of the $\mathrm{H}_{2} \mathrm{O}_{2}$ content, $2 \mathrm{~g}$ of sweet potato leaf powder was homogenized in $3 \mathrm{ml}$ of precooled acetone and centrifuged at $12,000 \times g$ for $30 \mathrm{~min}$. The $\mathrm{H}_{2} \mathrm{O}_{2}$ content was measured by determining the absorbance at $508 \mathrm{~nm}$. The content of malondialdehyde (MDA), which is considered to be an indicator of the degree of plant oxidative stress, was determined according to the method described by Chen et al. (2018), with slight modifications. Sweet potato samples $(2 \mathrm{~g})$ were homogenized in $10 \mathrm{ml}$ of $5 \%$ trichloroacetic acid and centrifuged at $12,000 \times \mathrm{g}$ for $30 \mathrm{~min}$ at $4^{\circ} \mathrm{C}$. The absorbance of the resulting supernatant was measured at 600 , 532 , and $450 \mathrm{~nm}$. The MDA content was calculated using the equation: MDA content $(\mathrm{nmol} / \mathrm{g})=\left[6.45 \times\left(A_{532}-A_{600}\right)-\right.$ $\left.0.56 \times A_{450}\right] \times V_{1} \times V_{3} /\left(V_{2} \times W\right)$, where $V_{1}, V_{2}$, and $V_{3}$ indicate the total volume of the solution obtained after the reaction $(\mathrm{ml})$, the volume of the extract solution used for the reaction $(\mathrm{ml})$, and the volume of the extract solution $(\mathrm{ml})$, respectively; $W$ indicates the mass of the sample (g).

\section{Determination of Lipoxygenase Activity in Sweet Potato Leaves}

Lipoxygenase (LOX) activity was determined by the procedure described by Surrey (1964). Sweet potato leaf powder (2 g) was homogenized in $5 \mathrm{ml}$ of $0.1 \mathrm{M} \mathrm{H}_{3} \mathrm{PO}_{4}$ buffer, $\mathrm{pH} 6.8$ [4\% PVPP (polyvinylpolypyrrolidone) and 1\% Triton X-100] and centrifuged at $12,000 \times g$ for $30 \mathrm{~min}$ at $4^{\circ} \mathrm{C}$. The obtained supernatant was considered the crude enzyme solution. The reaction solution contained $0.1 \mathrm{M} \mathrm{NaAc}$ buffer, $\mathrm{pH} 5.5,0.01 \mathrm{M}$ sodium linoleate, and the appropriate amount of crude enzyme solution. Absorbance was measured at $234 \mathrm{~nm}$. One unit of LOX was defined as a decrease of 0.01 optical density (OD) value in absorbance per minute, and the results were expressed as U/g FW.

\section{Data Analysis}

The physiological parameters of the sweet potatoes were analyzed using IBM SPSS 22.0 (IBM Corp., Armonk, NY, United States). The correlation among antioxidant enzyme activities, LOX activity, ROS-related indexes, and storage property of the different sweet potato cultivars, the heat map of the physiological 
parameters, and the PCA were assessed using the tools on the OmicShare platform ${ }^{1}$ (Gene Denovo, Guangzhou, China).

\section{RESULTS}

\section{Determination of the Storage Property of the 10 Sweet Potato Tubers}

Decay percentage is one of the basic indexes used to evaluate the storage properties of sweet potatoes. In this study, 10 sweet potato cultivars (i.e., Xu 32, Xu 55-2, Z 15-1, Shangshu 19, Sushu 16, Yanshu 5, Hanzi, Yushu, Zhezi 3, and Yan 25) were selected to evaluate the decay percentage during storage. The storage properties of the different sweet potato cultivars are shown in Table 1. Xu 32 was found to be a storage-tolerant cultivar; Xu 55-2, Z 15-1, Shangshu 19, Yushu, and Zhezi 3 above-medium storage-tolerant cultivars; Sushu 16, Yanshu 5, and Hanzi medium-storable cultivars; and Yan 25 a storagesensitive cultivar. Each sweet potato cultivar was assigned a storability score ranging from 1 (storage-sensitive) to 4 (storagetolerant). The weight loss percentage of the tubers after 290 days of storage was also determined. The lowest weight loss percentage (18.1\%) was observed in $\mathrm{Xu} 55-2$ and highest (67.1\%) in Sushu 16; however, no correlation was found between weight loss and storage property (Table 1).

${ }^{1}$ https://www.omicshare.com/

\section{Changes in $\alpha$-Amylase Activity in the Roots of the 10 Sweet Potato Cultivars During Storage}

Amylase activity is responsible for starch degradation during the postharvest storage of sweet potatoes. To evaluate the correlation between $\alpha$-amylase activity and storage property of the different cultivars, $\alpha$-amylase activity in sweet potato tubers was determined at 30-day intervals during the 290-day storage period. As shown in Figure 1A, before storage, the lowest $\alpha$-amylase activity was observed in the storage-tolerant

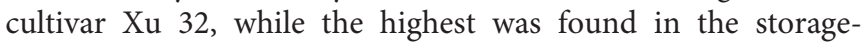
sensitive cultivar Yan 25. With increasing storage time, the $\alpha$-amylase activity of the 10 sweet potato root tubers showed an increasing trend, peaking at 290 DAS (Figure 1B). During storage, $\alpha$-amylase activity was lowest in the storage-tolerant cultivar Xu 32 and highest in the storage-sensitive cultivar Yan 25. Between days 30 and 90 of storage, the $\alpha$-amylase activity of the storage-tolerant and above-medium storage-tolerant cultivars was stable and remained at a low level, whereas that of the storage-sensitive cultivar Yan 25 showed a significant increase during this storage period. These results demonstrated that $\alpha$-amylase activity was lower in the storage-tolerant cultivar than in the storage-sensitive cultivar at all storage periods evaluated, and further suggested that $\alpha$-amylase activity is an important indicator of the storage property of the different sweet potato cultivars.

TABLE 1 | Storage property evaluation of 10 sweet potato cultivars, including Xu 32, Xu 55-2, Z 15-1, Shangshu 19, Sushu 16, Yanshu 5, Hanzi, Yushu, Zhezi 3, and Yan 25.

\begin{tabular}{|c|c|c|c|c|c|c|c|c|c|c|}
\hline Variety & Xu 32 & Xu 55-2 & Z 15-1 & Shangshu 19 & Yushu & Zhezi 3 & Sushu 16 & Yanshu 5 & Hanzi & Yan 25 \\
\hline $\begin{array}{l}\text { Decay } \\
\text { percentage }\end{array}$ & $<25 \%$ & $25-50 \%$ & $25-50 \%$ & $25-50 \%$ & $25-50 \%$ & $25-50 \%$ & $50-75 \%$ & $50-75 \%$ & $50-75 \%$ & $>75 \%$ \\
\hline Weight loss & $\begin{array}{c}33.5 \pm 3.2 \% \\
E\end{array}$ & $\begin{array}{c}18.1 \pm 2.0 \% \\
F\end{array}$ & $\begin{array}{c}19.2 \pm 3.4 \% \\
F\end{array}$ & $42.5 \pm 2.5 \% \mathrm{C}$ & $\begin{array}{c}34.6 \pm 2.7 \% \\
E\end{array}$ & $\begin{array}{c}37.9 \pm 6.0 \% \\
D\end{array}$ & $\begin{array}{c}67.1 \pm 4.1 \% \\
A\end{array}$ & $\begin{array}{c}37.6 \pm 2.1 \% \\
D\end{array}$ & $\begin{array}{c}33.7 \pm 6.2 \% \\
E\end{array}$ & $\begin{array}{c}51.7 \pm 2.4 \% \\
B\end{array}$ \\
\hline $\begin{array}{l}\text { Storage } \\
\text { level }\end{array}$ & $\begin{array}{l}\text { Storage- } \\
\text { tolerant }\end{array}$ & $\begin{array}{l}\text { Above- } \\
\text { moderate }\end{array}$ & $\begin{array}{l}\text { Above- } \\
\text { moderate }\end{array}$ & Above-moderate & $\begin{array}{l}\text { Above- } \\
\text { moderate }\end{array}$ & $\begin{array}{l}\text { Above- } \\
\text { moderate }\end{array}$ & Medium & Medium & Medium & $\begin{array}{l}\text { Storage- } \\
\text { sensitive }\end{array}$ \\
\hline Storability & 4 & 3 & 3 & 3 & 3 & 3 & 2 & 2 & 2 & 1 \\
\hline
\end{tabular}

score
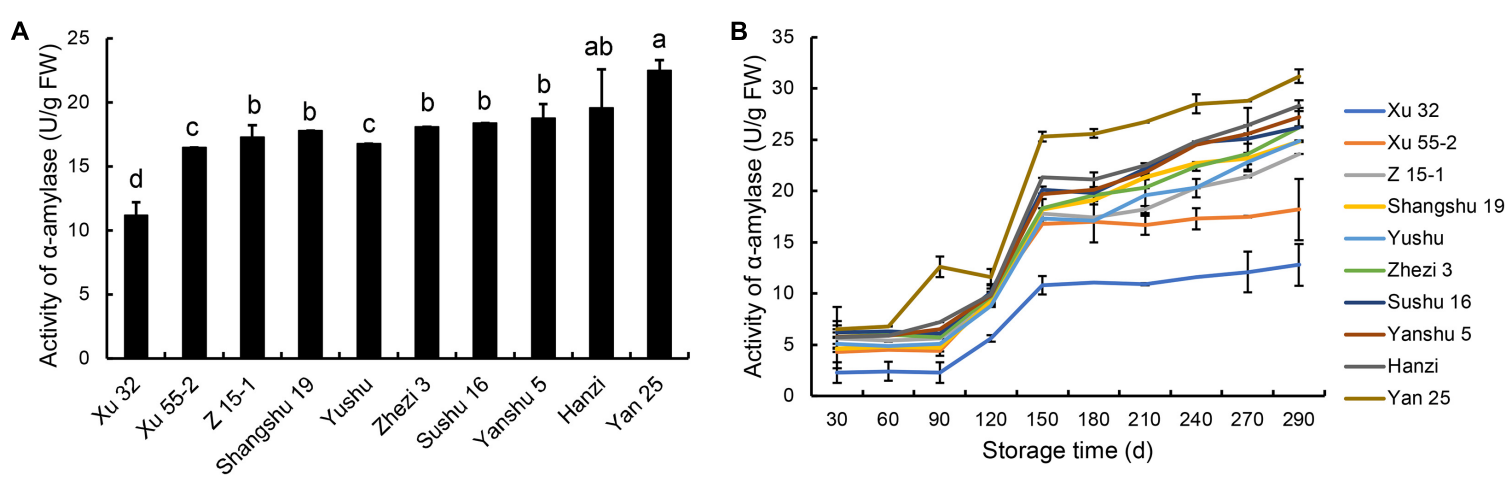

FIGURE 1 $\mid \alpha$-amylase activity in the tuberous roots of 10 sweet potato cultivars (i.e., Xu 32, Xu 55-2, Z 15-1, Shangshu 19, Sushu 16, Yanshu 5, Hanzi, Yushu, Zhezi 3, and Yan 25). (A) $\alpha$-amylase activity in the tuberous roots of 10 sweet potato cultivars before storage and (B) at 30 -day intervals during 290 days of postharvest storage. FW, fresh weight; $d$, days. Different letters above the columns in this figure and following figures stand for significant difference between two values $(p<0.05)$. 


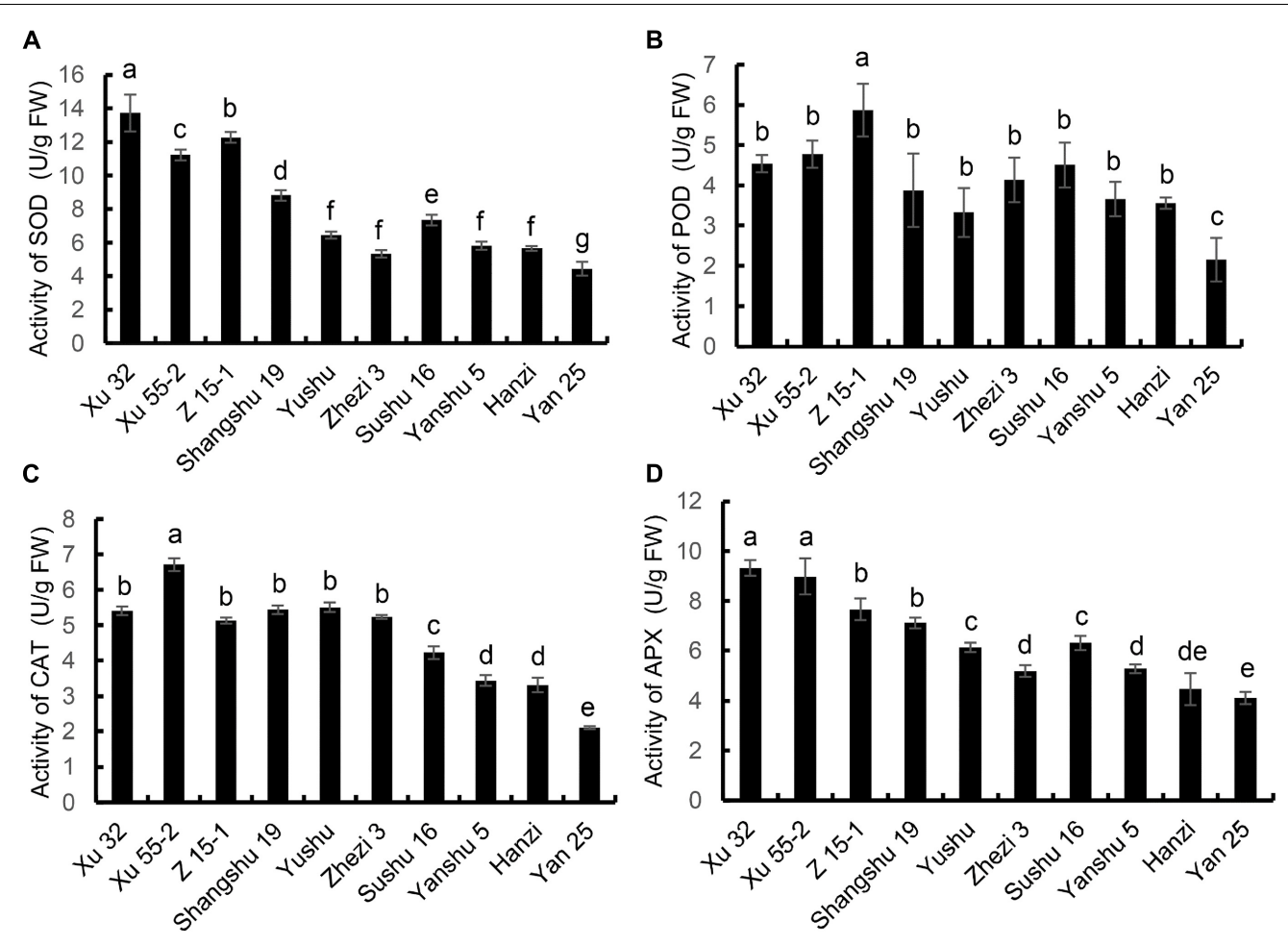

FIGURE 2 | The activities of (A) superoxide dismutase (SOD), (B) peroxidase (POD), (C) catalase (CAT), and (D) ascorbate peroxidase (APX) in the leaves of 10 sweet potato cultivars (i.e., Xu 32, Xu 55-2, Z 15-1, Shangshu 19, Sushu 16, Yanshu 5, Hanzi, Yushu, Zhezi 3, and Yan 25). Data are presented as means \pm SD $(n=3)$. FW, fresh weight.
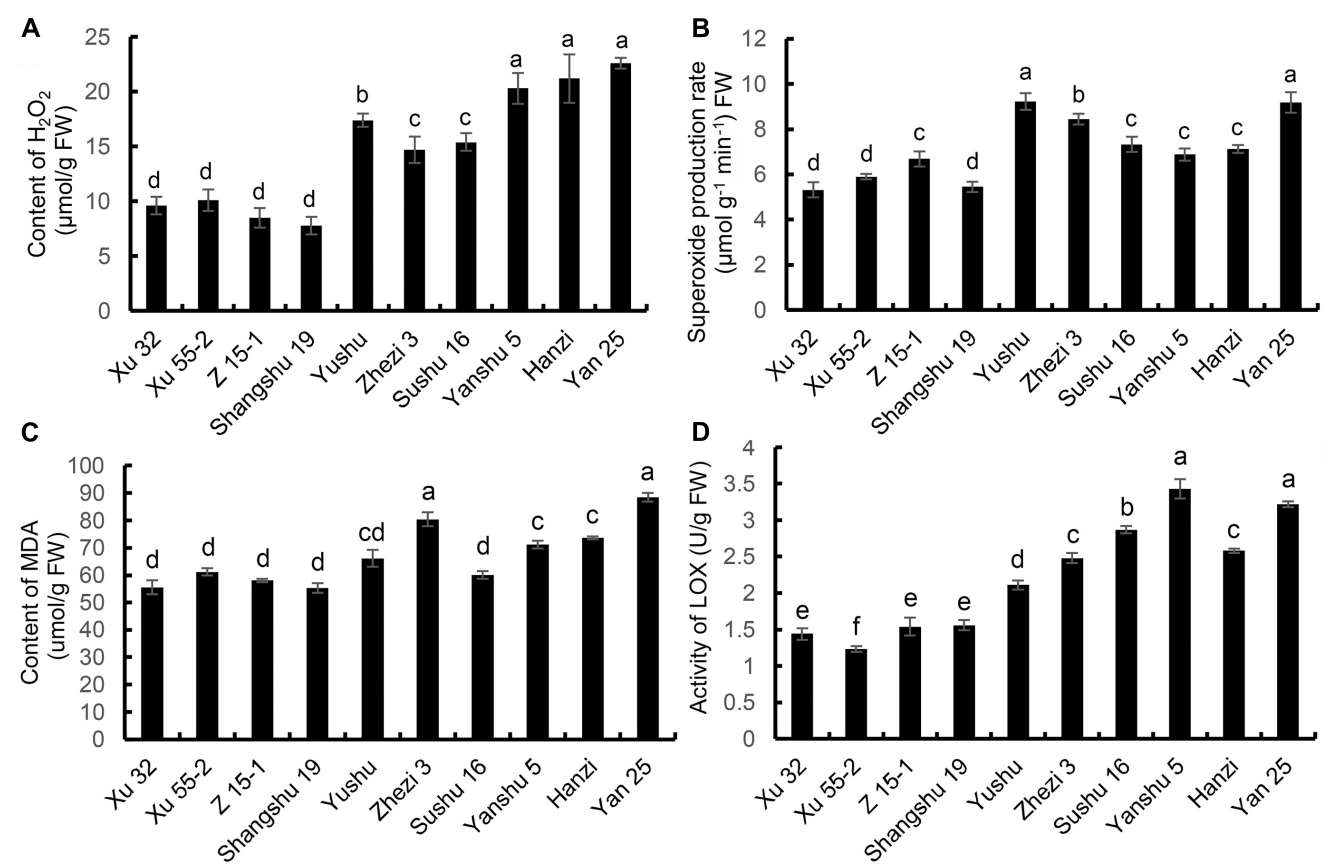

FIGURE 3 | (A) $\mathrm{H}_{2} \mathrm{O}_{2}$ content, (B) $\mathrm{O}_{2} \cdot{ }^{-}$production rate, (C) malondialdehyde (MDA) content, and (D) lipoxygenase (LOX) activity in the leaves of the 10 sweet potato cultivars. Data are presented as means $\pm \mathrm{SD}(n=3)$. FW, fresh weight. 


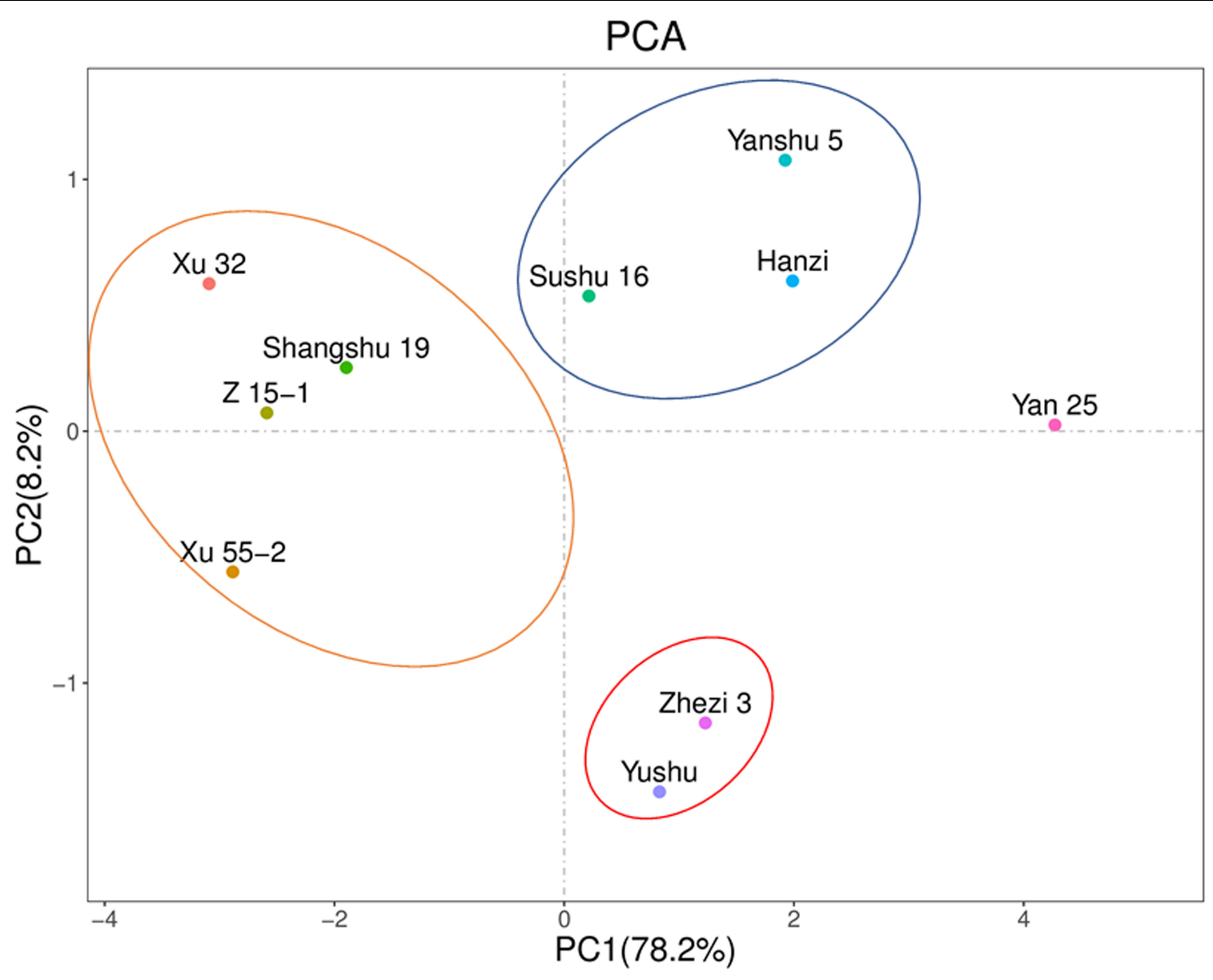

FIGURE 4 | Principal component analysis based on antioxidant-related enzyme activities and reactive oxygen species (ROS) contents in 10 sweet potato cultivars (i.e., Xu 32, Xu 55-2, Z 15-1, Shangshu 19, Sushu 16, Yanshu 5, Hanzi, Yushu, Zhezi 3, and Yan 25).

\section{Analysis of the Activities of Antioxidant Enzymes in the Leaves of the 10 Sweet Potato Cultivars}

The activities of antioxidant enzymes are required for ROS scavenging during sweet potato storage. Accordingly, we sought to determine whether a correlation existed between antioxidant enzyme activity in the leaves and tuber storage property. The results showed that SOD activity was highest in the storagetolerant cultivar Xu 32 and lowest in Yan 25 (Figure 2A). SOD activity was 3.1-fold higher in $\mathrm{Xu} 32$ than in the storage-sensitive cultivar Yan 25. As shown in Figure 2B, POD enzyme activity was generally consistent with the trend for SOD activity across the 10 sweet potato cultivars, with Yan 25 showing the lowest activity and Z 15-1 the highest (2.73-fold higher compared with that of Yan 25). The activities of CAT and APX in the 10 cultivars are shown in Figures 2C,D, respectively. CAT and APX activities were higher in the cultivars that showed better storage property (Xu 32, Z 15-1, Xu 55-2, Shangshu 19, Yushu, and Zhezi 3 vs. Sushu 16, Yanshu 5, Hanzi, and Yan 25). The Xu 55-2 cultivar displayed the highest CAT activity and Yan 25 the lowest. Meanwhile, APX activity was highest in Xu 32 and lowest in Yan 25. The above results indicated that the better the storage property, the higher the activities of antioxidant-related enzymes.

\section{Changes in Superoxide Anion Radical, Hydrogen Peroxide, and Malondialdehyde Contents and Lipoxygenase Enzyme Activity in the Leaves of the Different Sweet Potato Cultivars}

The changes in $\mathrm{H}_{2} \mathrm{O}_{2}$ content in the leaves of the sweet potatoes are shown in Figure 3A. The $\mathrm{H}_{2} \mathrm{O}_{2}$ content was lowest in the $\mathrm{Xu}$ 32, Xu 55-2, Z 15-1, and Shangshu 19 cultivars and highest in Yan 25. The $\mathrm{H}_{2} \mathrm{O}_{2}$ content in Yan 25 was 2.89-fold higher than that of Shangshu19. The $\mathrm{H}_{2} \mathrm{O}_{2}$ content in $\mathrm{Xu} 32, \mathrm{Xu}$ 55-2, and $\mathrm{Z} \mathrm{15-1,}$ the cultivars with stronger storage performance, was significantly lower than that of Sushu 16, Yanshu 5, Hanzi, Yushu, and Zhezi 3 , cultivars with reduced storage property. $\mathrm{O}_{2} \cdot{ }^{-}$production and MDA content showed a pattern similar to that for the $\mathrm{H}_{2} \mathrm{O}_{2}$ content (Figures 3B,C). The rate of $\mathrm{O}_{2} \cdot{ }^{-}$production was lowest 
in the storage-tolerant cultivar $\mathrm{Xu} 32$ and highest in the storagesensitive cultivar Yan 25 (1.72-fold that of $\mathrm{Xu}$ 32). The MDA content showed a gradual increase with decreasing the storage property of sweet potato. Yan 25 exhibited the highest MDA content, which was 1.6-fold that of Shangshu 19, the cultivar that displayed the lowest MDA content. As shown in Figure 3D, LOX activity was generally low in the leaves of the Xu 32, Xu 55-2, Z 15 1 , and Shangshu19 cultivars and was lowest in $\mathrm{Xu}$ 55-2. Overall, LOX activity was higher in the leaves of the Yan 25, Sushu 16, and Yanshu 5 cultivars than in those of Zhezi 3, Sushu 16, and Hanzi. LOX activity in Yanshu 5 and Yan 25 was 2.79- and 2.62fold, respectively, that of $\mathrm{Xu} 55-2$. These findings indicated that the cultivars with better storability had lower $\mathrm{O}_{2} \cdot{ }^{-}, \mathrm{H}_{2} \mathrm{O}_{2}$, and MDA contents, as well as lower LOX enzyme activity.

\section{Principal Component Analysis of Antioxidant Enzyme Activities and Reactive Oxygen Species Metabolites in the Leaves of the Different Sweet Potato Cultivars}

The PCA showed that PC1 and PC2 accounted for 78.2 and 8.2\%, respectively, of the variability in the data (Figure 4). Storagetolerant and storage-sensitive cultivars were clearly clustered in PC1. Yanshu 5, Hanzi, and Sushu 16 were clustered together, as were $\mathrm{Xu}$ 32, $\mathrm{Xu}$ 55-2, Z 15-1, and Shangshu 19, Yushu, and Zhezi 3. The variety showing the highest positive loading on PC1 was Yan 25, and the variety that showed the lowest loading on PC2 was Yanshu 5. These observations suggested that a positive correlation exists between antioxidant capacity and storage property among the different sweet potato cultivars.

\section{Analysis of the Correlation Between Physiological Indexes and Storage Property in the Different Sweet Potato Cultivars}

Then, the correlation among storage properties (i.e., $\alpha$-amylase activity and rot percentage) of sweet potato roots and leaf parameters [i.e., ROS production $\left(\mathrm{H}_{2} \mathrm{O}_{2}, \mathrm{O}_{2} \cdot^{-}\right.$, and MDA) and antioxidant enzyme activities (i.e., POD, APX, SOD, CAT, and LOX)] was analyzed (Figure 5). A positive correlation was found among storage property and POD, APX, SOD, and CAT activities, as well as among $\alpha$-amylase activity, LOX activity, and $\mathrm{O}_{2} \cdot{ }^{-}, \mathrm{H}_{2} \mathrm{O}_{2}$, and MDA contents. In addition, SOD, POD, CAT, and APX activities and storage properties were negatively correlated with LOX, $\alpha$-amylase activities and $\mathrm{O}_{2}{ }^{-}$, $\mathrm{H}_{2} \mathrm{O}_{2}$, and MDA contents. SOD activity was significantly and positively correlated with APX activity $(r=0.948)$ and highly and negatively correlated with $\mathrm{H}_{2} \mathrm{O}_{2}$ contents $(r=-0.841)$. POD activity was highly and positively correlated with SOD activity $(r=0.764)$ and highly and negatively correlated with $\mathrm{H}_{2} \mathrm{O}_{2}$ levels $(r=-0.767)$. CAT activity was highly and positively correlated with APX activity $(r=0.799)$ and negatively correlated with LOX activity $(r=-0.850)$. LOX activity showed a negative correlation with APX activity $(r=-0.853)$ and a positive correlation with the $\mathrm{H}_{2} \mathrm{O}_{2}$ content $(r=0.877)$. A negative correlation was found between $\mathrm{H}_{2} \mathrm{O}_{2}$ content and SOD activity $(r=-0.841)$. Besides, there was a significant and negative correlation between $\alpha$-amylase activity and storage property $(r=-0.915)$ and a positive correlation between $\alpha$-amylase activity and MDA content $(r=0.777)$. Overall, the correlation analysis indicated that the storage property of sweet potato roots is positively associated with antioxidative enzyme activity and negatively correlated with ROS metabolites in sweet potato leaves. The positive correlation detected among the activities of the antioxidant enzymes suggested that they are activated and cooperated in scavenging ROS.

\section{Heat Map Analysis of Antioxidant-Related Indexes and Cluster Analysis of the Relationship Among the Different Sweet Potato Cultivars}

To further verify the relationship between the antioxidant capacity and storage property of the different sweet potato cultivars, we generated a heat map of the antioxidant enzymeand ROS-related indexes in the sweet potato leaves and the storage property of sweet potato ( $\alpha$-amylase activity). As shown in Figure 6, the sweet potato cultivars (i.e., Xu 32, Xu 55-2, Shangshu 19, and Z 15-1) with better storability were clustered together and showed higher activities of antioxidant related enzymes (i.e., POD, SOD, APX, and CAT), but significantly lower LOX and $\alpha$-amylase activities, $\mathrm{O}_{2} \cdot{ }^{-}$production rates, and $\mathrm{H}_{2} \mathrm{O}_{2}$ and MDA contents relative to the storage-sensitive cultivars (i.e., Sushu 16, Yanshu 5, Hanzi, Yan 25, Yushu, and Zhezi 3). Xu 32 , the cultivar with the best storage property, had the lowest $\alpha$-amylase activity, while the storage-sensitive cultivar, Yan 25, had the highest.

\section{DISCUSSION}

Owing to its tropical origins, the tuberous roots of the sweet potato are susceptible to chilling stress ( $\mathrm{Li}$ et al., 2018). Moreover, sweet potato decays easily during storage due to its high water content (Sugri et al., 2017). Even at appropriate storage temperatures, crops still undergo deteriorative changes resulting from the activity of internal factors, such as ROS, a key contributor to postharvest senescence (Wang et al., 2019; Guo et al., 2021). ROS can be produced in plants during many metabolic reactions, but particularly in chloroplasts and mitochondria during senescence. Throughout this process, the antioxidant defense system, comprising both enzymatic and nonenzymatic antioxidants, is activated to scavenge excessive ROS, thereby preventing cellular damage (Nie et al., 2020). Antioxidant capacity was reported to be related to the storage properties of different sweet potato cultivars (de Araujo et al., 2021), while increased antioxidant enzyme activity was found to be positively correlated with sweet potato storability (Tang et al., 2019). However, whether a correlation exists between antioxidant enzyme activity in sweet potato leaves and the storage properties of the tubers has not been determined. To address this, in this study, we evaluated whether the antioxidant capacity of 


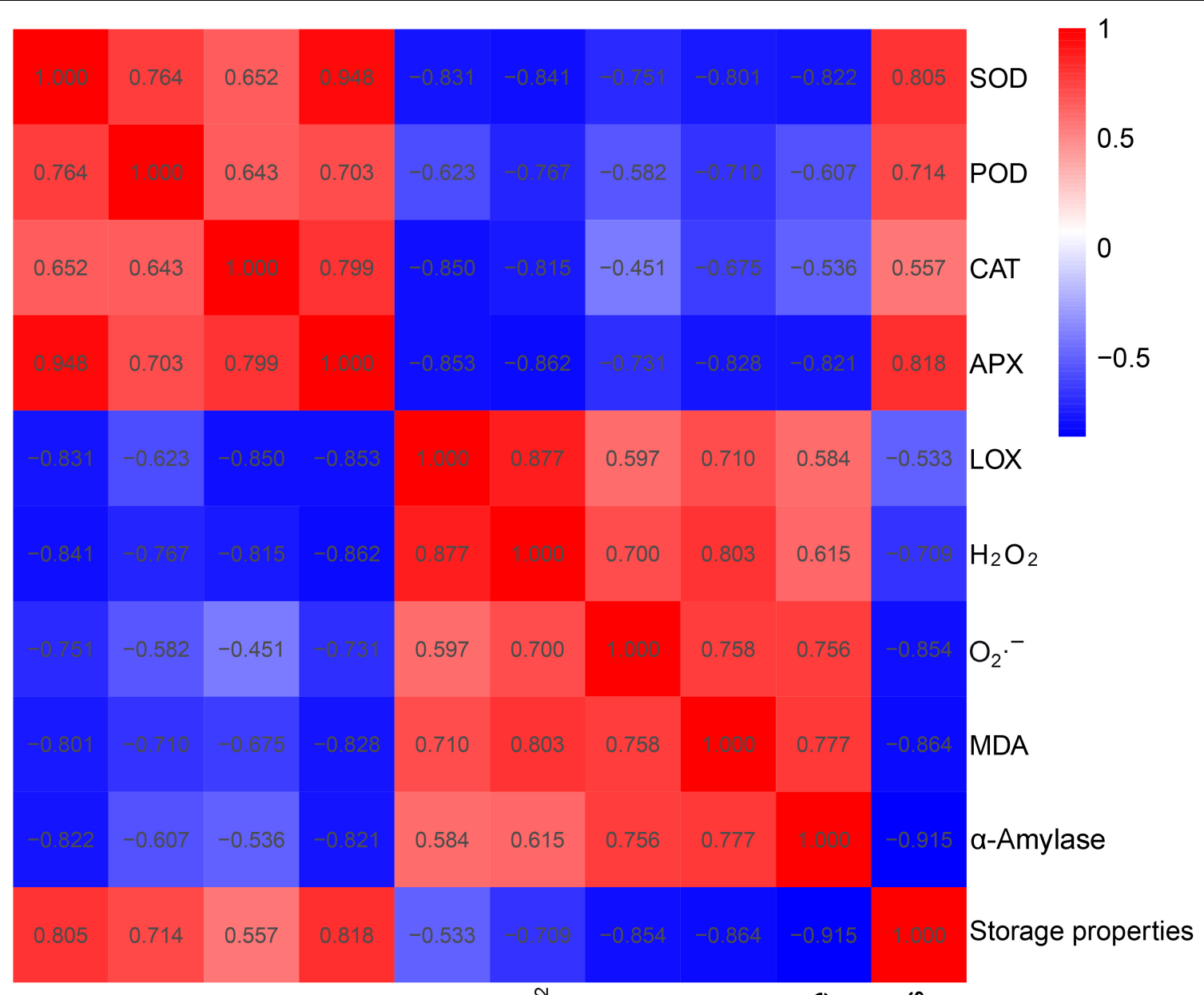

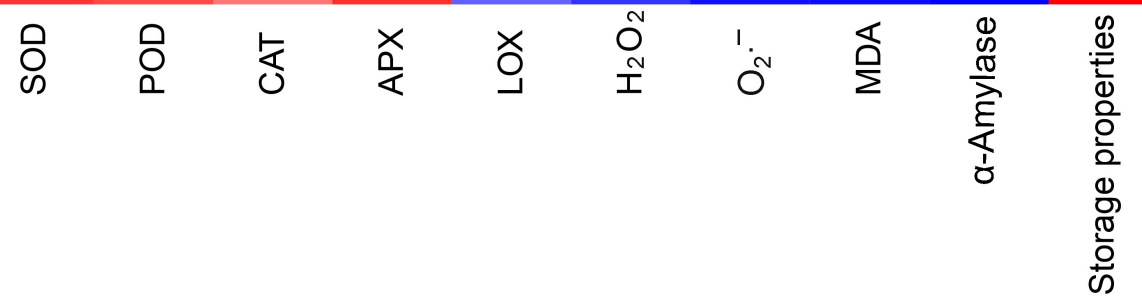

FIGURE 5 | Correlation analysis among SOD, POD, APX, CAT, and LOX activities, superoxide anion $\left(\mathrm{O}_{2} \cdot{ }^{-}\right)$production, and $\mathrm{MDA}$ and $\mathrm{H}_{2} \mathrm{O}_{2}$ contents in the leaves and storage property and $\alpha$-amylase in the roots of 10 sweet potato cultivars (i.e., Xu 32, Xu 55-2, Z15-1, Shangshu 19, Sushu 16, Yanshu 5, Hanzi, Yushu, Zhezi 3, and Yan 25).

sweet potato leaves is positively correlated with the storage property of sweet potato using 10 sweet potato cultivars as the experimental material.

The storability of the 10 cultivars was first determined based on decay percentage at 290 DAS. We found that $\mathrm{Xu} 32$ is a storage-tolerant cultivar; Yan 25 is a storage-sensitive cultivar; $\mathrm{Xu}$ 55-2, Z 15-1, Shangshu 19, Yushu, and Zhezi 3 are above-medium storage-tolerant cultivars; and Sushu 16, Yanshu 5, and Hanzi are medium-storable cultivars. We also determined the weight loss percentage of the tubers at 290 DAS but found no association between weight loss and decay percentage. Accordingly, only the latter was used to categorize the storage property of sweet potato tubers. Starch constitutes an important carbohydrate reserve in tuberous roots of sweet potatoes, and amylase activity is required for starch degradation during storage (Lu et al., 2020). In this study, we found that $\alpha$-amylase activity was lowest in the storagetolerant cultivar $\mathrm{Xu} 32$ and highest in the storage-sensitive cultivar Yan 25. A significant increase in $\alpha$-amylase activity was observed in tubers during storage, especially in the more storagesensitive cultivars, suggesting that a correlation exists between $\alpha$-amylase activity and storage property of tubers (Figure 1), which was consistent with the results of Lu et al. (2020). We further found that sweet potato tuber storability is highly correlated with the antioxidant capacity of the sweet potato leaves, which provides a convenient means for the screening of storage-tolerant sweet potato cultivars. 


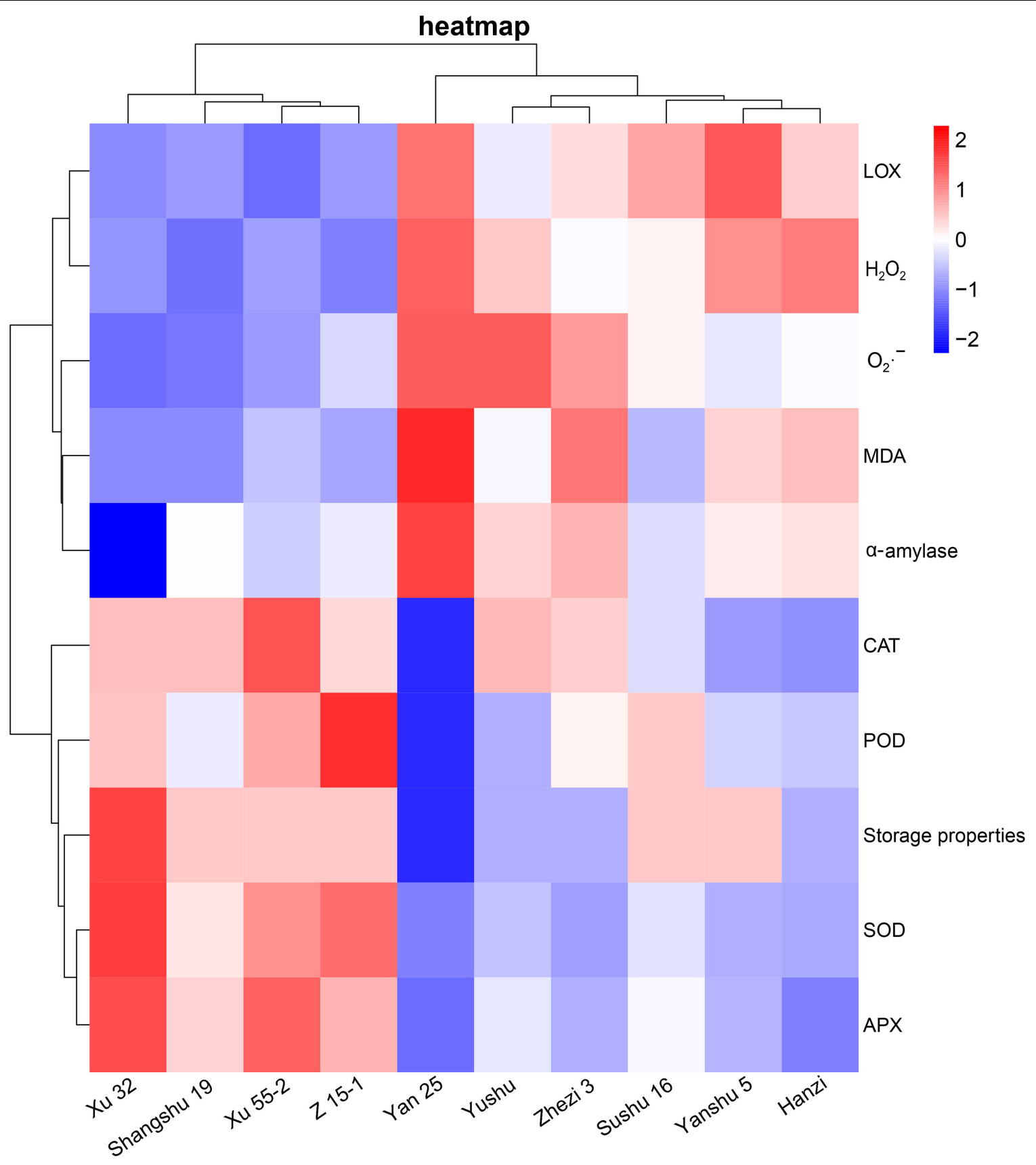

FIGURE 6 | Heat map analysis of antioxidant enzyme (i.e., SOD, POD, APX, CAT), $\alpha$-amylase, and LOX activities and ROS-related indexes (i.e., $\mathrm{O}_{2} \cdot{ }^{-}$, $\mathrm{H}_{2} \mathrm{O}_{2}$, and MDA) in 10 sweet potato cultivars (i.e., Xu 32, Xu 55-2, Z15-1, Shangshu 19, Sushu 16, Yanshu 5, Hanzi, Yushu, Zhezi 3, and Yan 25).

Numerous studies have shown that ROS accumulates in fruit and vegetable during storage. For instance, ROS accumulation in longan postharvest leads to a gradual increase in cell membrane permeability and the destruction of cell membrane structure (Lin et al., 2005). Additionally, hydrogen sulfide treatment can increase the antioxidant capacity of strawberry, thereby prolonging its shelf life (Hu et al., 2012). Combined, these observations suggest that antioxidant capacity is intrinsic to a specific cultivar and is a key determinant of postharvest senescence. However, the relationship between the storage property of different sweet potato cultivars and the antioxidant capacity of sweet potato leaves still needs further investigation. In this study, we found that antioxidant enzyme (i.e., CAT, POD, APX, and SOD) activity in the leaves of the storage-tolerant cultivars Xu 32, Xu 55-2, and Z 15-1 remained at higher levels compared with those of the storage-sensitive cultivars Yan 25, Sushu 16, Yanshu 5, and Hanzi, whereas the opposite was seen for LOX activity. Besides, the storage-tolerant cultivar Xu 32 and the 


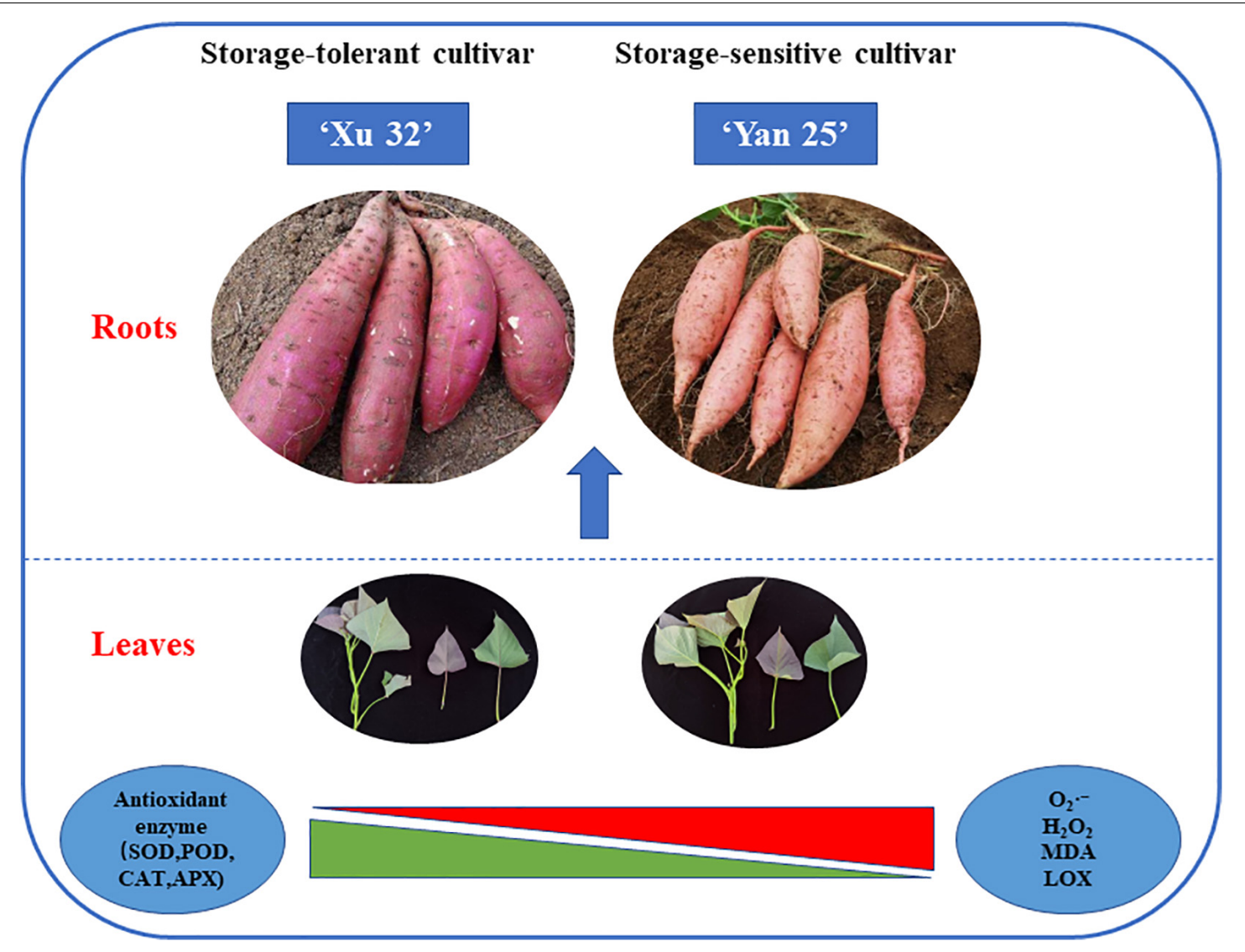

FIGURE 7 | Schematic diagram showing that ROS and MDA levels; LOX, SOD, POD, APX, and CAT activities in sweet potato leaves are highly associated with the storage property of different sweet potato tubers.

above-moderate storage-tolerant cultivars Xu 55-2 and Shangshu 19 contained lower levels of ROS metabolites when compared with those of the storage-sensitive cultivar Yan 25, all of which suggested that antioxidant capacity is positively correlated with sweet potato storability.

Furthermore, correlation and heat map analysis showed that there was a prominent association between the antioxidant capacity of sweet potato leaves and the storage property of sweet potato tubers, while antioxidant enzyme activity was negatively correlated with the levels of ROS metabolites and positively correlated with storage property. Moreover, $\alpha$-amylase activity was found to be negatively correlated with storage property, suggesting that $\alpha$-amylase activity is also a valuable index for evaluating the storage potential of sweet potato tubers. PCA indicated that sweet potato cultivars with similar antioxidant enzyme activities, such as Xu 32, Xu 55-2, Z 15-1, and Shangshu 19, were clustered together, as were Yanshu 5, Hanzi, and Sushu 16 (Figure 3). Overall, these results were consistent with the storage properties of the different cultivars and sweet potato varieties with similar antioxidant enzyme activities. The growth environment, soil, fertilizer and water management, temperature, light, and other external conditions can all affect the storage performance of sweet potato, while the ecological environment can significantly affect sweet potato quality (Yan et al., 2017).
Rosenthal and Jansky (2008) reported that antioxidant activity in potato growing in a high-yield production environment was usually the highest and increased during storage, indicative of the importance of antioxidant enzymes for potato storability. Additionally, ultrasound treatment can inhibit the browning of fresh-cut sweet potatoes by reducing PPO and POD activities while improving total antioxidant capacity (Pan et al., 2020). Moreover, low-temperature conditioning at $10^{\circ} \mathrm{C}$ can induce antioxidant enzyme activity in tuberous roots and protect tubers from chilling injury when subjected to subsequent cold storage at $4^{\circ} \mathrm{C}$ ( $\mathrm{Li}$ et al., 2018). Together, these findings suggest that the antioxidative enzyme system is critical for protecting the sweet potato from postharvest senescence and decay. As shown in Figure 7, antioxidant enzymes are required for maintaining ROS metabolic balance, while accumulated ROS may negatively influence the storage property of sweet potato tubers.

Overall, this study provides strong evidence that the antioxidant capacity of leaves in different sweet potato cultivars is positively correlated with their storability. We further found that $\alpha$-amylase activity in sweet potato tubers is negatively correlated with storage property, suggesting that $\alpha$-amylase activity may represent a valuable index for evaluating the storage potential of sweet potato tubers. Finally, given that the characterization of storage property in different sweet potato cultivars is a 
time-consuming process, this study provides a convenient means for evaluating the storage properties of sweet potatoes by measuring the antioxidant capacity in sweet potato leaves.

\section{DATA AVAILABILITY STATEMENT}

The original contributions presented in the study are included in the article/supplementary material, further inquiries can be directed to the corresponding author/s.

\section{AUTHOR CONTRIBUTIONS}

$\mathrm{H}-\mathrm{HS}$, K-DH, G-FY, and $\mathrm{HZ}$ conceived and designed the experiments. H-HS, Z-LZ, and D-LZ performed the experiments. Z-LZ, D-LZ, HZ, and X-YC analyzed the data.

\section{REFERENCES}

Ali, S., Anjum, M. A., Nawaz, A., Naz, S., Ejaz, S., Sardar, H., et al. (2020). Tragacanth gum coating modulates oxidative stress and maintains quality of harvested apricot fruits. Int. J. Biol. Macromol. 163, 2439-2447. doi: 10.1016/j. ijbiomac.2020.09.179

Chen, H. Z., Zhang, M., Bhandari, B., and Guo, Z. (2018). Evaluation of the freshness of fresh-cut green bell pepper (Capsicum annuum var. grossum) using electronic nose. LWT 87, 77-84. doi: 10.1016/j.lwt.2017.08.052

de Araujo, N. O., de Sousa Santos, M. N., de Araujo, F. F., Véras, M. L. M., de Jesus Tello, J. P., da Silva Arruda, R., et al. (2021). Balance between oxidative stress and the antioxidant system is associated with the level of cold tolerance in sweet potato roots. Postharvest Biol. Technol. 172:111359. doi: 10.1016/j.postharvbio. 2020.111359

Fan, W., Deng, G., Wang, H., Zhang, H., and Zhang, P. (2015). Elevated compartmentalization of $\mathrm{Na}^{+}$into vacuoles improves salt and cold stress tolerance in sweet potato (Ipomoea batatas). Physiol. Plant 154, 560-571. doi: $10.1111 / \mathrm{ppl} .12301$

Food and Agriculture Organization (FAO). (2019). FAOSTAT Agriculture Data. Available online at: https://www.fao.org/faostat/en/.

Garcì-Limones, C., Hervás, A., Navas-Cortés, J. A., Jiménez-Dìaz, R. M., and Tena, M. (2002). Induction of an antioxidant enzyme system and other oxidative stress markers associated with compatible and incompatible interactions between chickpea (Cicer arietinum L.) and Fusarium oxysporum f. sp. ciceris. Physiol. Mol. Plant Pathol. 61, 325-337. doi: 10.1006/pmpp.2003. 0445

Ge, Y., Hu, K. D., Wang, S. S., Hu, L. Y., Chen, X. Y., Li, Y. H., et al. (2017). Hydrogen sulfide alleviates postharvest ripening and senescence of banana by antagonizing the effect of ethylene. PLoS One 12:e180113. doi: 10.1371/journal. pone. 0180113

Guo, S., Li, T., Wu, C., Fan, G., Wang, H., and Shen, D. (2021). Melatonin and 1-methylcyclopropene treatments on delay senescence of apricots during postharvest cold storage by enhancing antioxidant system activity. J. Food Process. Preserv. 45:e15863. doi: 10.1111/jfpp.15863

Hu, L. Y., Hu, S. L., Wu, J., Li, Y. H., Zheng, J. L., Wei, Z. J., et al. (2012). Hydrogen sulfide prolongs postharvest shelf life of strawberry and plays an antioxidative role in fruits. J. Agric. Food Chem. 60, 8684-8693. doi: 10.1021/jf300728h

Ji, C. Y., Chung, W. H., Kim, H. S., Jung, W. Y., Kang, L., Jeong, J. C., et al. (2017). Transcriptome profiling of sweetpotato tuberous roots during low temperature storage. Plant Physiol. Biochem. 112, 97-108. doi: 10.1016/j.plaphy.2016.12.021

Kang, L., Ji, C. Y., Kim, S. H., Ke, Q., Park, S. C., Kim, H. S., et al. (2017). Suppression of the $\beta$-carotene hydroxylase gene increases $\beta$-carotene content and tolerance to abiotic stress in transgenic sweetpotato plants. Plant Physiol. Biochem. 117, 24-33. doi: 10.1016/j.plaphy.2017.05.017

Li, X., Yang, H., and Lu, G. (2018). Low-temperature conditioning combined with cold storage inducing rapid sweetening of sweetpotato tuberous roots (Ipomoea
K-DH, G-FY, and H-HS wrote the manuscript. K-DH, G-FY, and $\mathrm{ZH}$ interpreted the data and revised the manuscript. All authors contributed to the article and approved the submitted version.

\section{FUNDING}

This study was supported by the National Key R\&D Program of China (2019YFD1000700 and 2019YFD1000701), the National Key R\&D Program of China (2019YFD1001300 and 2019YFD1001303), the China Agriculture Research System (CARS-10-B1), the National Natural Science Foundation of China (32170315, 31970312, 31901993, 31970200, and 31670278), the Natural Science Foundations of Anhui Province (1908085MC72), and the Fundamental Research Funds for the Central Universities (JZ2021HGPA0063).

batatas (L.) Lam) while inhibiting chilling injury. Postharvest Biol. Technol. 142, 1-9. doi: 10.1016/j.postharvbio.2018.04.002

Lin, H. T., Xi, Y. F., and Chen, S. J. (2005). The relationship between the desiccation-induced browning and the metabolism of active oxygen and phenolics in pericarp of postharvest longan fruit. J. Physiol. Mol. Biol. Plants 31, 287-297. doi: 10.1360/aps040074

Lu, P., Li, X., Janaswamy, S., Chi, C., Chen, L., Wu, Y., et al. (2020). Insights on the structure and digestibility of sweet potato starch: effect of postharvest storage of sweet potato roots. Int. J. Biol. Macromol. 145, 694-700. doi: 10.1016/j.ijbiomac. 2019.12.151

Lurie, S., Klein, J. D., and Arie, R. B. (1991). Prestorage heat treatment delays development of superficial scald on Granny Smith'apples. Hortscience 26, 166167. doi: 10.21273/HORTSCI.26.2.166

Miśkiewicz, E., Ivanov, A. G., Williams, J. P., Khan, M. U., Falk, S., and Huner, N. P. (2000). Photosynthetic acclimation of the filamentous cyanobacterium, Plectonema boryanum UTEX 485, to temperature and light. Plant Cell Physiol. 41, 767-775. doi: $10.1093 / \mathrm{pcp} / 41.6 .767$

Mittler, R. (2002). Oxidative stress, antioxidants and stress tolerance. Trends Plant Sci. 7, 405-410. doi: 10.1016/S1360-1385(02)02312-9

Mwanga, R. O., Andrade, M. I., Carey, E. E., Low, J. W., Yencho, G. C., and Grüneberg, W. J. (2017). "Sweetpotato (Ipomoea batatas L.)," in Genetic Improvement of Tropical Crops, eds H. Campos and P. D. S. Caligari (Cham: Springer), 181-218.

Nie, Z., Huang, Q., Chen, C., Wan, C., and Chen, J. (2020). Chitosan coating alleviates postharvest juice sac granulation by mitigating ROS accumulation in harvested pummelo (Citrus grandis L. Osbeck) during room temperature storage. Postharvest Biol. Technol. 169:111309. doi: 10.1016/j.postharvbio.2020. 111309

Pan, Y., Chen, L., Pang, L., Chen, X., Jia, X., and Li, X. (2020). Ultrasound treatment inhibits browning and improves antioxidant capacity of fresh-cut sweet potato during cold storage. RSC Adv. 10, 9193-9202. doi: 10.1039/C9RA06 $418 \mathrm{D}$

Qin, G., Meng, X., Wang, Q., and Tian, S. (2009). Oxidative damage of mitochondrial proteins contributes to fruit senescence: a redox proteomics analysis. J. Proteome Res. 8, 2449-2462. doi: 10.1021/pr801046m

Rosenthal, S., and Jansky, S. (2008). Effect of production site and storage on antioxidant levels in specialty potato (Solanum tuberosum L.) tubers. J. Sci. Food Agric. 88, 2087-2092. doi: 10.1002/jsfa.3318

Sugri, I., Maalekuu, B. K., Kusi, F., and Gaveh, E. (2017). Quality and shelf-life of sweet potato as influenced by storage and postharvest treatments. Trends Hort. Res. 7, 1-10. doi: 10.3923/thr.2017.1.10

Surrey, K. (1964). Spectrophotometric method for determination of lipoxidase activity. Plant Physiol. 39:65. doi: 10.1104/pp.39.1.65

Takahata, Y., Noda, T., and Sato, T. (1995). Changes in carbohydrates and enzyme activities of sweetpotato lines during storage. J. Agric. Food Chem. 43, 19231928. doi: 10.1021/jf00055a031 
Tang, J., Wang, S. Q., Hu, K. D., Huang, Z. Q., Li, Y. H., Han, Z., et al. (2019). Antioxidative capacity is highly associated with the storage property of tuberous roots in different sweetpotato cultivars. Sci. Rep. 9:11141. doi: 10.1038/s41598019-47604-8

Tian, S., Qin, G., and Li, B. (2013). Reactive oxygen species involved in regulating fruit senescence and fungal pathogenicity. Plant Mol. Biol. 82, 593-602. doi: 10.1007/s11103-013-0035-2

Wang, S., Nie, S., and Zhu, F. (2016). Chemical constituents and health effects of sweet potato. Food Res. Int. 89, 90-116. doi: 10.1016/j.foodres.2016.08.032

Wang, S. Q., Tang, J., Hu, K. D., Huang, Z. Q., Yang, F., Zhang, H. Y., et al. (2019). Antioxidative system in sweet potato root is activated by low-temperature storage. J. Sci. Food Agric. 99, 3824-3833. doi: 10.1002/jsfa.9604

Yan, H., Li, Q., Zhang, Y., Wang, X., Liu, Y., Kou, M., et al. (2017). Effects of soil and environment on quality traits of purple-fleshed sweetpotato. Agric. Sci. Technol. 18, 516-523. doi: 10.16175/j.cnki.1009-4229.2017.03.034

Zhang, K., Wu, Z., Tang, D., Luo, K., Lu, H., Liu, Y., et al. (2017). Comparative transcriptome analysis reveals critical function of sucrose metabolism relatedenzymes in starch accumulation in the storage root of sweet potato. Front. Plant Sci. 8:914. doi: 10.3389/fpls.2017.00914

Zhang, Y., and Fang, B. (2006). Descriptors and Data Standard for Sweetpotato [Ipomoea batatas (L.) Lam.]. Beijing: China Agricultural Press.

Zhang, Z., Nakano, K., and Maezawa, S. (2009). Comparison of the antioxidant enzymes of broccoli after cold or heat shock treatment at different storage temperatures. Postharvest Biol. Technol. 54, 101-105. doi: 10.1016/j. postharvbio.2009.05.006

Zhang, Z., Wheatley, C. C., and Corke, H. (2002). Biochemical changes during storage of sweet potato roots differing in dry matter content. Postharvest Biol. Technol 24, 317-325. doi: 10.1016/S0925-5214(01)00149-1
Zhang, Z. L., Qu, W. Q., and Li, X. F. (2009). Experimental Guidance of Plant Physiology. Beijing: Higher Education Press, 111-112.

Zhao, H., Shu, C., Fan, X., Cao, J., and Jiang, W. (2018). Near-freezing temperature storage prolongs storage period and improves quality and antioxidant capacity of nectarines. Sci. Hortic. 228, 196-203. doi: 10.1016/j.scienta.2017.1 0.032

Zimmermann, P., Heinlein, C., Orendi, G., and Zentgraf, U. (2006). Senescence-specific regulation of catalases in Arabidopsis thaliana (L.) Heynh. Plant Cell Environ. 29, 1049-1060. doi: 10.1111/j.1365-3040.2005.0 1459.x

Conflict of Interest: The authors declare that the research was conducted in the absence of any commercial or financial relationships that could be construed as a potential conflict of interest.

Publisher's Note: All claims expressed in this article are solely those of the authors and do not necessarily represent those of their affiliated organizations, or those of the publisher, the editors and the reviewers. Any product that may be evaluated in this article, or claim that may be made by its manufacturer, is not guaranteed or endorsed by the publisher.

Copyright (c) 2021 Song, Zhou, Zhao, Tang, Li, Han, Chen, Hu, Yao and Zhang. This is an open-access article distributed under the terms of the Creative Commons Attribution License (CC BY). The use, distribution or reproduction in other forums is permitted, provided the original author(s) and the copyright owner(s) are credited and that the original publication in this journal is cited, in accordance with accepted academic practice. No use, distribution or reproduction is permitted which does not comply with these terms. 